\title{
SIMULATION TOOLS FOR POWER ELECTRONICS COURSES, BASED IN JAVA TECHNOLOGIES
}

\author{
Carlos A. Canesin ${ }^{1}$, Flávio A. S. Gonçalves ${ }^{2}$ and Leonardo P. Sampaio ${ }^{3}$ \\ São Paulo State University, UNESP - FEIS \\ Department of Electrical Engineering \\ 15385-000 Ilha Solteira, SP - Brazil

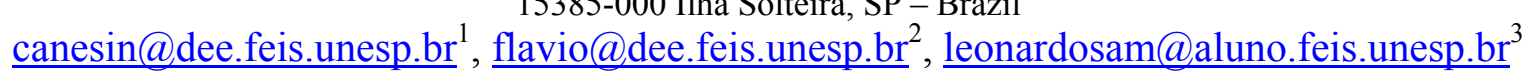

\begin{abstract}
This paper presents interactive power electronics educational tools. These interactive tools make use of the benefits of Java language to provide a dynamic and interactive approach in order to simulate steadystate idealized rectifiers (uncontrolled and controlled; single-phase and three-phase). Additionally, this paper discusses the development and the usage of the Java applet programs to assist the teaching of conventional power electronics rectifier circuits, and to serve as a first design tool for the basic laboratory experiments in the power electronics courses. Some results were confronted with a well-known simulator package in order to validate the developed interactive simulation applets.
\end{abstract}

Keywords - E-learning, Education Tools, Java Applets, Power Electronics Teaching.

\section{INTRODUCTION}

Education is one of the most important foundations for supporting the social development in a country. In the last decades, researchers have been trying the refinement of concepts/techniques and the development of new tools to support the improvement of the educational processes [1].

The traditional form of teaching presented in the classrooms can be complemented with the usage of interactive systems based on computers. These systems can provide a learning environment with high quality leading to the improvement of the student's learning quality, and consequently the educator's productivity [2].

The evolution in the computers associated with the rapid emergence of the World Wide Web (WWW) and its associated tools have provided educators with a powerful and effective mechanism of information delivery. This environment can easily incorporate the latest hypermedia technologies (hypertexts, interactive simulations, videos/sounds, databases, remote controlled instruments) to compose and to manage educational courses, virtual laboratories and virtual classrooms [3, 4].

The main advantages of educational systems based on WWW are independence of time and space, a simple and familiar interface, due to methodology based on web browser, and conditions for simultaneous attendances [3-5].

Until few years ago, the teaching of power electronics circuits was based on methodologies on which concepts were presented in a static way. However, in order to illustrate in a

Manuscript received on February 17, 2008. Revised on March 11, 2008 Recommended by the Editors of the Special Section W. Suemitsu and J. A. Pomilio. dynamic and interactive way concepts usually difficult to reproduce in traditional classrooms, using the conventional explanations and static tools, these approaches have been supplemented with computer simulations and oriented object graphic tools.

The learning or teaching of a technical engineering subject, mainly in power electronics area, is often complicated because there is a large number of possible reaction of a system in the presence of parameter changes. This way, the system dynamic behavior can be explained easily in many cases if these dynamics were presented in the interactive form, through an interactive training environment. Additionally, it enables the student to avoid a passive watching role at learning and pushes him to active participation in the learning process [6].

The circuit simulation packages became essential tools in several engineering courses, and strongly recommended for complementary and advanced circuit analysis, once they provide complex models with almost realistic behavior. Moreover, some of these approaches based on specific simulation packages require software installation, and the student needs to learn first how to use the simulation tool before starts to study the desired topic. Usually, this task can become inefficient and confuse if the student faces up to your first course using simulation packages [7-8].

Last years, several researchers are looking for the development of distributed environment tools in order to assist the teaching of basic circuit systems with a high interaction level, and that can be executed in an easy and straight way. Thereby, Java is one of the most used platforms for the development of these tools, due to their intrinsic advantages [9-13].

In this context, most of the interactive tools are focused on "what-if" simulations based on moving bars increasing or decreasing parameters of the circuits. In other words, the circuit situations are performed without the use of real values for the circuit's parameters. Thus, the sense for real values is missed for the students, and it is well-known that in this learning stage they are very important.

Furthermore, it is also important to give to the students a practical experience provided by laboratory experiments. Thus, the students can enjoy the real experiment and virtual simulation together if the laboratory experiments were supplemented with interactive simulations. The real experiment gives to the students a sense of practical testing, where they can see some effects (diode reverse recovery, switching losses, and other non-idealities) not considered in the idealized models presented in the virtual simulation. Therefore, students can perform a relative comparison among lab-experiences and the theoretical concepts introduced in 
the classes provided on-line by the interactive simulation tools [14-17].

In this context, this paper proposes several improved interactive Java applets increasing the resources available for the WWW-HTML-based course in basic power electronics circuits to be used both in the normal classes and the laboratory classes. The applets deal with the main aspects of the basic uncontrolled and controlled rectifiers and they can be used to calculate important parameters such as power factor, input current total harmonic distortion, root-meansquare (rms) values, average and peak values, load voltage waveform with/without commutation angle, and to provide a script file to be used in the simulator package PSPICE.

\section{DEVELOPMENT AND ORGANIZATION OF JAVA APPLETS}

The proposed Java applets were developed to assist power electronics education at undergraduate level in engineering courses. The main goal of proposed Java applets is to produce an interactive visualization of simulations for idealized circuit of power electronics in steady state, which are used as an instructional tool embedded in a WWWHTML-based course in the classes and in the laboratories. Therefore, the results of simulation processed in steady-state may be visually presented to learners in real time, illustrating important concepts that are difficult to be performed in traditional classes and laboratories.

These Java applets were previously developed and published in [16-18], whose initial goal was an easy and flexible environment to study and learn power electronics. In this new development stage, the objectives are improvements in the programming methods (classes, interfaces and heritage) to make easy the tools maintenance and updating, and the development of novel Java applets providing a more complete environment to assist power electronics courses. For instance, Figure 1 shows in simplified way how the schematic circuits have been mounted over the novel applets, and Figure 2 shows a comparison between previous and new Java Applet applications.

The graphical user interfaces (GUI) for simulation applets were designed with four distinct sectors, as shown in Figure 3 , with the purpose of allowing the student to go through menu options to change circuit parameters, run and view

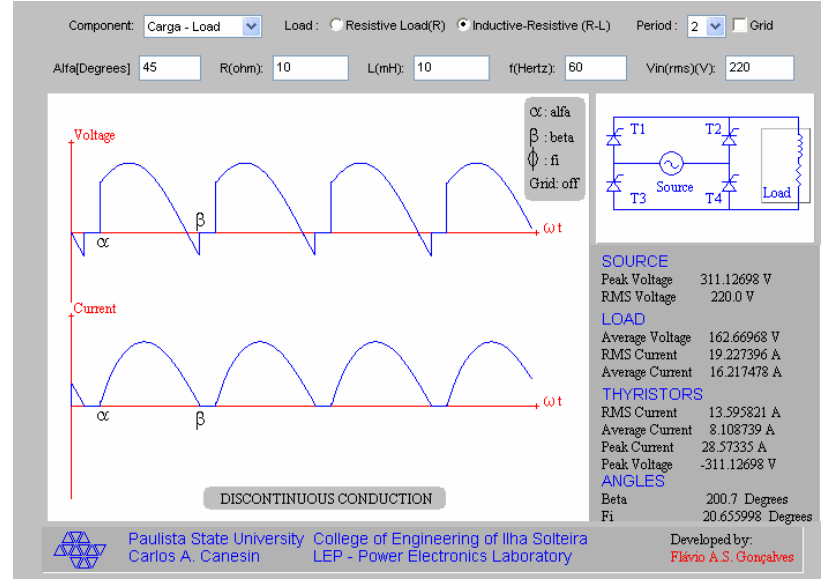

(a) Previous Version simulation results in an easy and straight way.

Some sectors can initiate new simulations. They are denominated active, and the remainders are passive. The passive sectors provide the feedback information to the student through waveforms and calculated values.

The sectors 1 and 2 are active. In these sectors the student can specify all circuit parameters and select desired component of the circuit to perform the required simulation analysis. Essentially, the student can set the load type ( $\mathrm{R}$ or R-L) and magnitudes, amplitude and frequency of the input voltage, and the fire angle in the case of the controlled rectifiers.

The sector 2 is a circuit schematic drawing module (CSDM). Its structure is based on a $5 \times 7$ array. The circuit is created considering values/attributes in array (rows and columns). Therefore, a database has been developed containing information of layout, orientation, position and numeric codes for the components. In addition, the CSDM module is interconnected with waveforms and main modules, it receives parameters regarding operational stages and shows the current flowing through circuit's paths.

The sectors 3 and 4 are passive sectors. In the sector 3 are shown the voltage and current waveforms for the selected circuit component in the sector 2 . This sector is connected with sector 4 and the abacus module. In this way, one can modify parameters directly in sector 1 or indirectly using the abacus waveform located in "Graphic" guide.
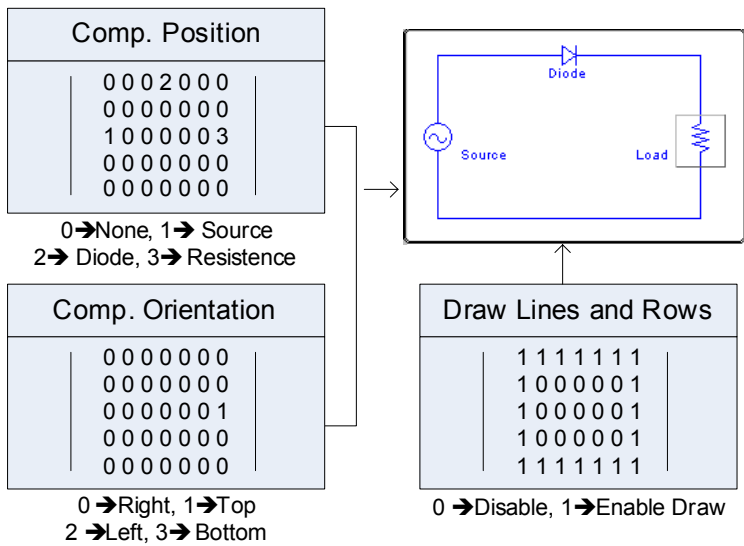

Fig. 1. The simplified method for mounting the schematic circuit over the novel applets, half-wave diode rectifier example.

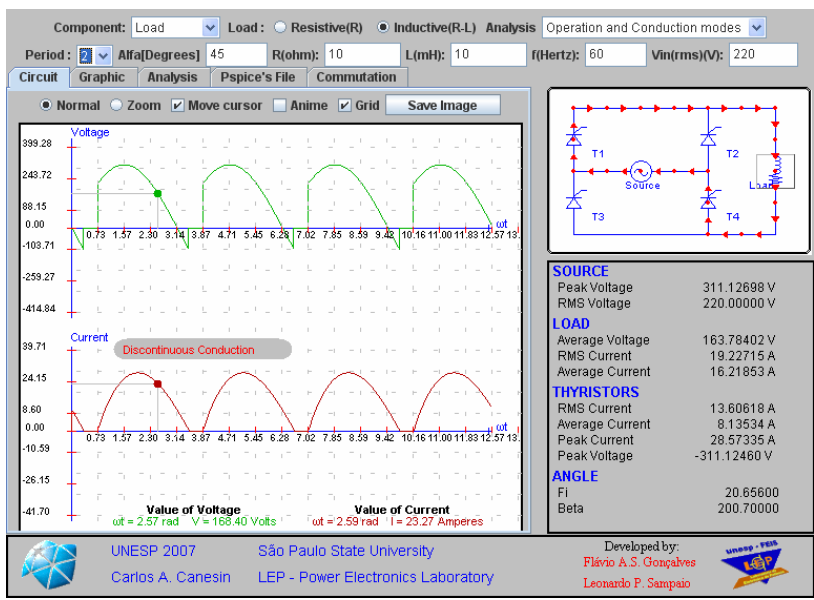

(b) New Version

Fig. 2. A comparison between previous version and the new version of Java Applet applications. 


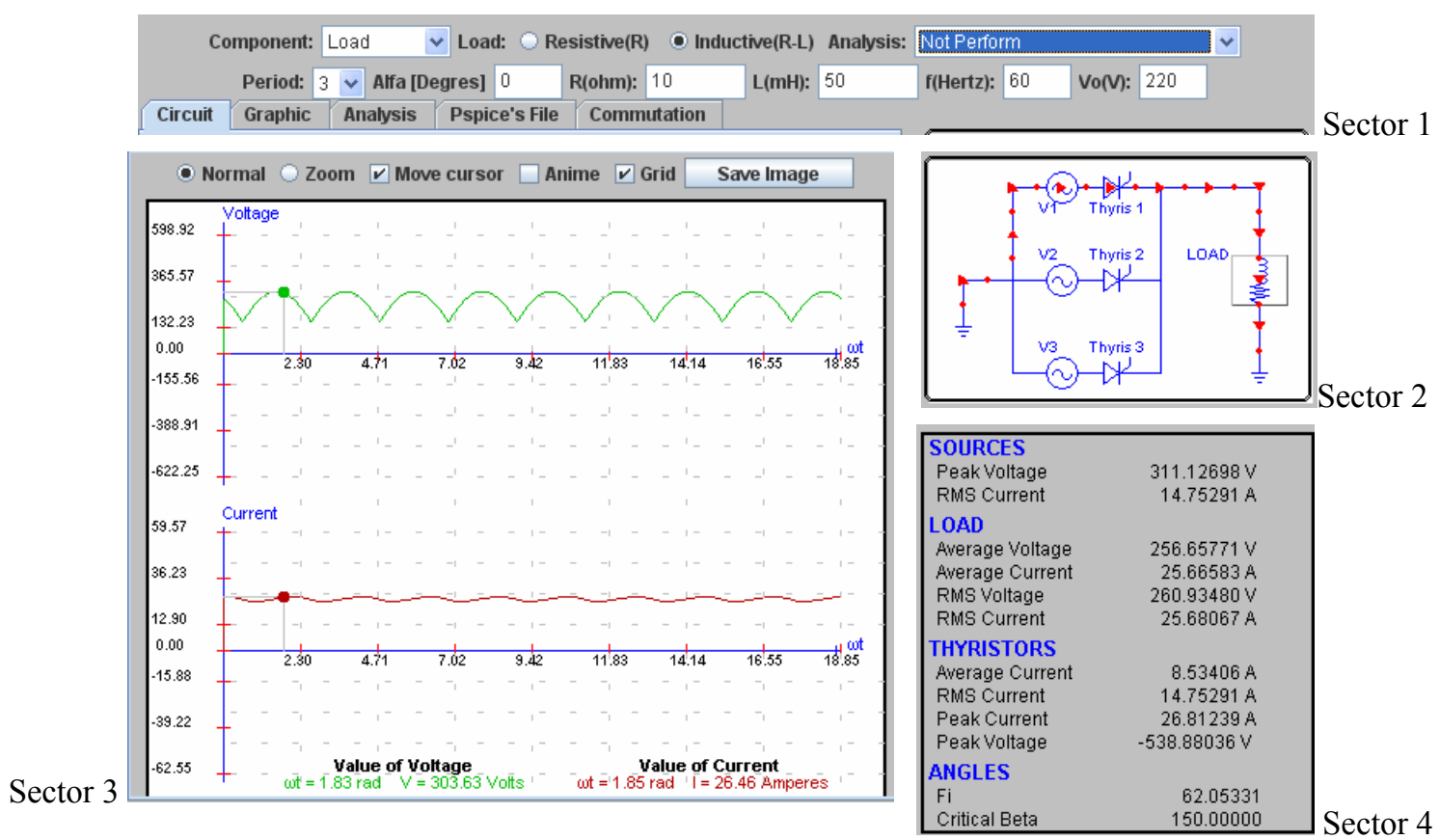

Fig. 3. Graphical User Interface designed for the simulation applets.

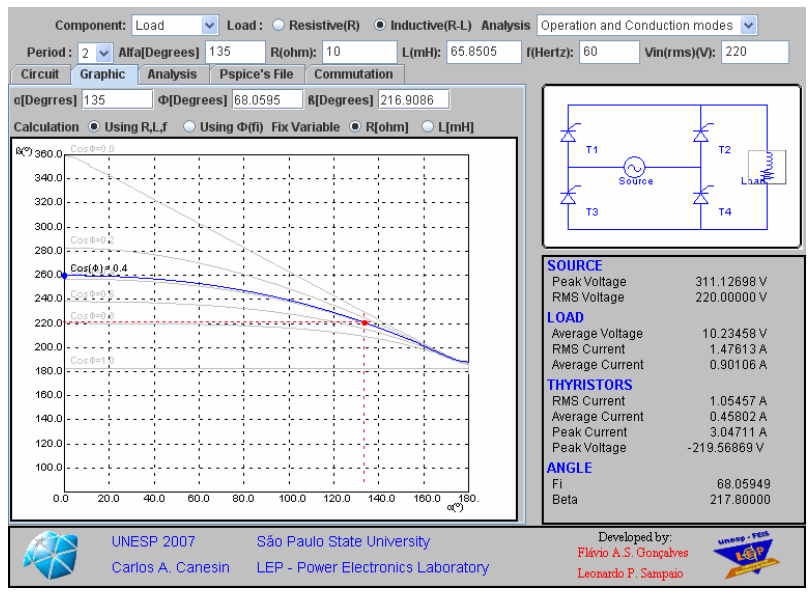

Fig. 4. Single-phase full-bridge controlled rectifier: "Graphic" guide, "Puschlowski" abacus.

The abacus module draws the "Puschlowski" abacus for the selected topologic structure, and provides a draggable cursor on abacus graphic. Thus, one can modify the parameters of sector 1 dynamically and easily, through the usage of the mouse, as shown in Figure 4.

It should be noticed that, in the old Java applet applications the main values showed in sector 4 were computed using basic equations of each rectifier structure. In the novel Java applets, sector 4 receives voltage and current waveforms from sector 3 , and computes their peak, rms and average values through Fourier series algorithm. Furthermore, the sector 3 allows the visualization of input current harmonic content using the "Analysis" guide option. Additionally, if inconsistent values were specified by the students in the simulation options, warnings will be presented in passive sectors informing the error causes.

\section{DEVELOPED JAVA APPLETS}

Currently, the available interactive circuit simulations include:

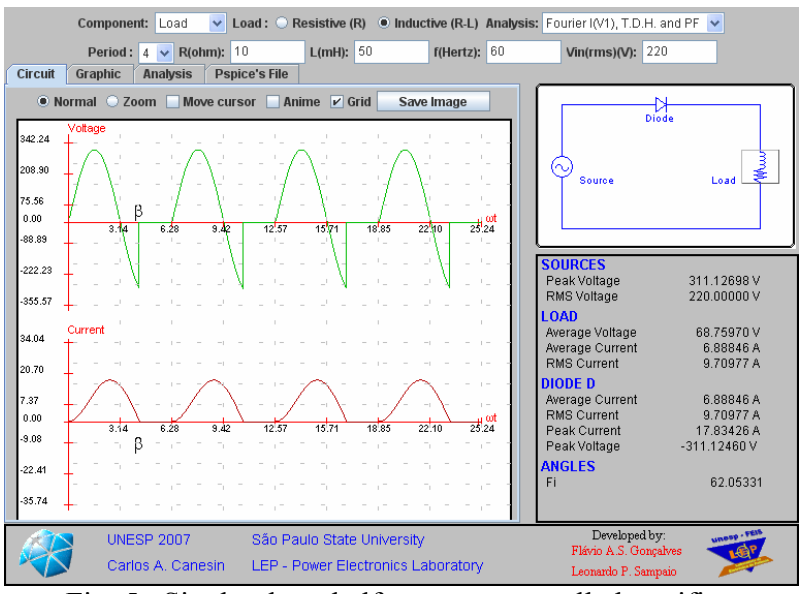

Fig. 5. Single-phase half-wave uncontrolled rectifier: waveforms for the resistive-inductive load.

\section{A. Uncontrolled Rectifiers (Idealized Circuits)}

- Single-Phase: half-wave diode rectifier, half-wave diode rectifier with freewheeling diode, full-wave center-tapped diode rectifier, and full-wave fullbridge diode rectifier;

- Three-phase: three-pulse diode rectifier, and sixpulse full-bridge diode rectifier.

\section{B. Controlled Rectifiers (Idealized Circuits)}

- Single-Phase: half-wave thyristor rectifier, halfwave thyristor rectifier with freewheeling diode, full-wave center-tapped thyristor rectifier, fullwave full-bridge thyristor rectifier, and semicontrolled thyristor/diode-bridge rectifier;

- Three-Phase: three-pulse thyristor rectifier, sixpulse full-bridge thyristor rectifier, and semicontrolled thyristor/diode-bridge rectifier.

In order to provide some examples, Figures 4 to 9 show a couple of rectifier simulations performed using the proposed interactive simulation tools. 
One can verify in proposed educational tools that students are allowed to vary the circuit parameters and examine instantly the effect of these changes on the main circuit variables. Therefore, the output current and voltage waveforms, as well as some rms, average and peak circuit values can be investigated in the simulation applets for different input parameters, as shown in Figures 4 and 5.

Figure 4 shows an example of abacus module interaction, in this case the "Puschlowski" abacus, for the single-phase full bridge controlled rectifier. The tool draws some waveforms in gray color considering different load angle values $(\Phi)$, allowing better visualization of whole operational limits, and it draws in blue color the abacus concerning load angle specified for simulation. Additionally, two draggable cursors are available in blue abacus. The blue one allows varying the load angle, and the red cursor allows varying the fire angle $(\alpha)$, according to load angle and extinction current angle $(\beta)$.

Moreover, additional features for the proposed improved simulation applets include the Fourier analysis option for some specified circuit variables, animation mode showing the operational stages along with the current flow paths, waveform zoom tool with cursor option, abacus mode where the students can select the rectifier operation point through normalized graphics, and Pspice option where the simulation netlist script regarding the interactive simulation is provided using Pspice standard.

Figure 6 shows an example illustrating the option "move cursor", when this option is selected and the red point regarding the current waveform position dragged and moved by the mouse the actual amplitudes of current and voltage are shown in the bottom of section 3 and current flow path is shown in the power circuit picture (sector 2). The current flow is visualized by moving colored red arrows and the students can pass through all the topological stages of the rectifier topology in analysis.

Other available option is the "anime mode" that provides the same information regarding the topological stages, but in an automatic way as an animation. In addition, for all interactive simulation tools, a Fourier analysis can be performed using the input current through one of the input voltage sources, or the current and voltage across the load.

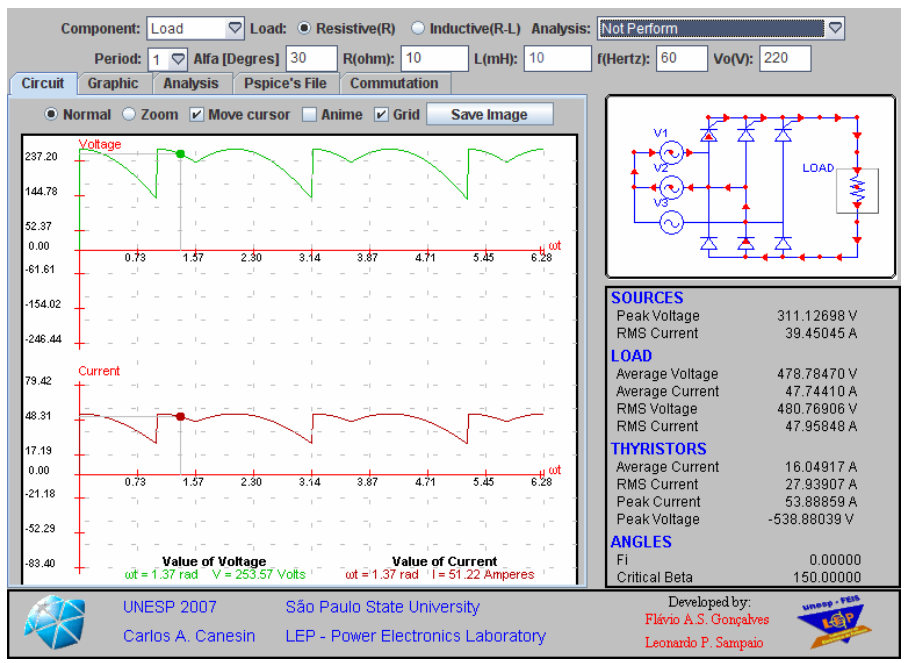

Fig. 6. Three-phase semi-controlled thyristor/diode-bridge rectifier, example of operational stages using "Move cursor".
In accordance with Figure 7, the Fourier analysis results are presented in a table format, where the harmonic content is depicted through each component order and their associated amplitudes in peak values, frequency, and the phases in degrees. Furthermore, the power factor (P.F.) and total harmonic distortion (T.H.D.) for the input current can be also computed.

In order to validate the developed simulation models, the results were confronted with the results obtained from a wellknow simulator package, PSPICE, where the rectifier circuits were created employing idealized models for the semiconductors and simulated using the script file provided by the java application, as shown in the example of Figure 8 .

The semiconductors cannot turn-on and turn-off instantaneously, if there are series inductances with the input voltage sources. Therefore, "Commutation" guide allows the visualization of the series inductance effects. Thus, through sector 3 this module receives the waveform and estimates the average voltage drop in the load, showing the load voltage waveform considering the non-null commutation angle. Additionally, in this module, one can insert parameters as commutation angle or series inductance, in order to estimate the voltage drop in the load, as shown in Figure 9.

Figure 10 shows the comparison for the results regarding the single-phase semi-controlled thyristor/diode-bridge rectifier. In accordance with the difference between the results obtained, Tables I and II, the simulation applet got an error relatively small, and it has proved to be reasonably accurate taking into account the simplicity of the utilized algorithms and errors in converting pixel to voltage or current for magnitude values.

\section{WWW-COURSE}

The complete platform to assist the power electronics classes includes new online content over www, through open and distributed environment. This www-course platform allows free access to all available Java Applets, and provides the complete classroom material, including exercises and proposed problems. Thus, all users have the possibility to study the content through internet, and can transfer online contents to their personal computer, through free of charge and distributed tools, independent of time and space.

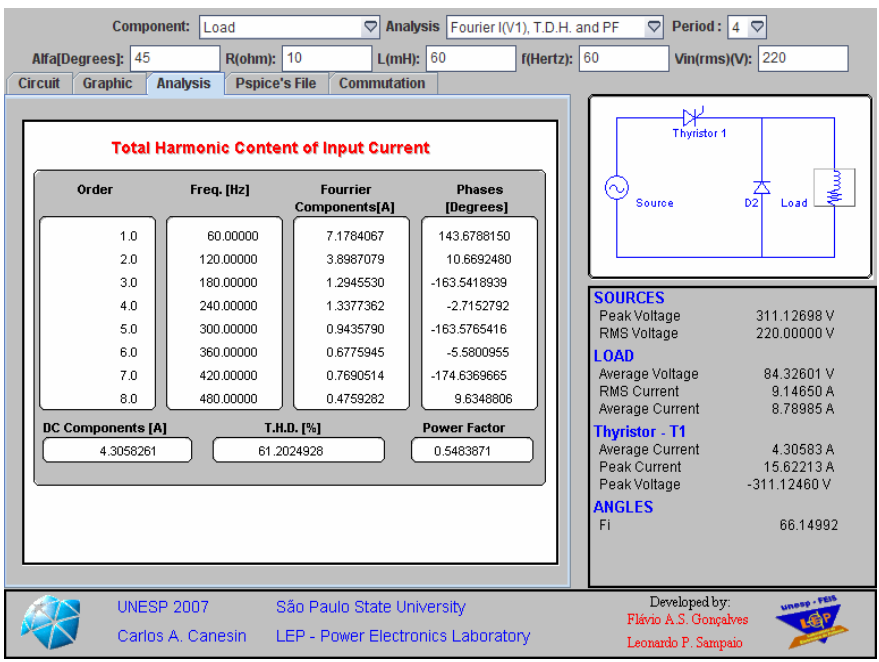

Fig. 7. Single-phase half-wave controlled rectifier with freewheeling diode, example of input current harmonic analysis. 


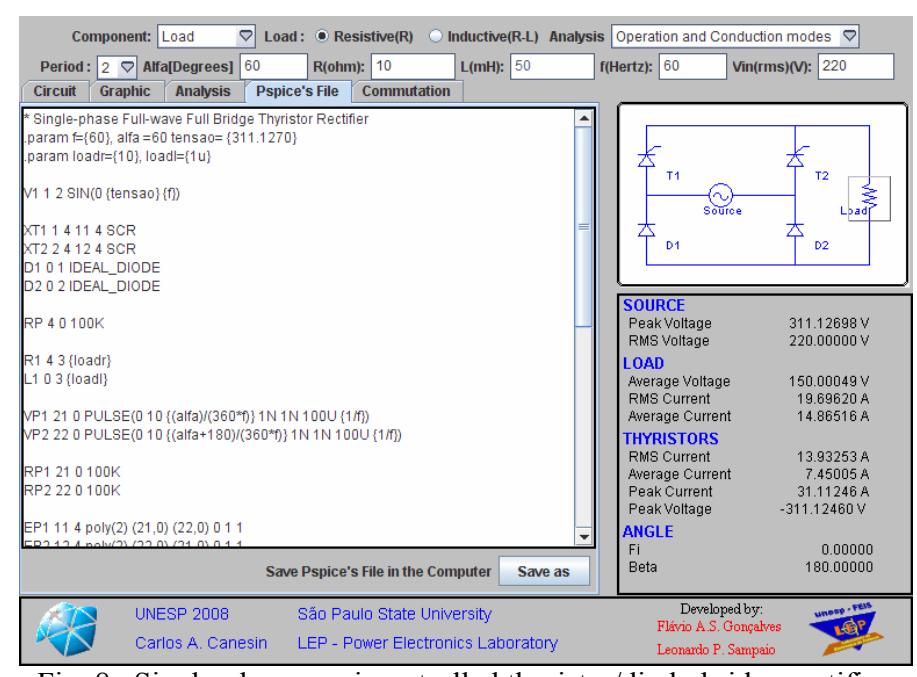

Fig. 8. Single-phase semi-controlled thyristor/diode-bridge rectifier, Pspice script example.

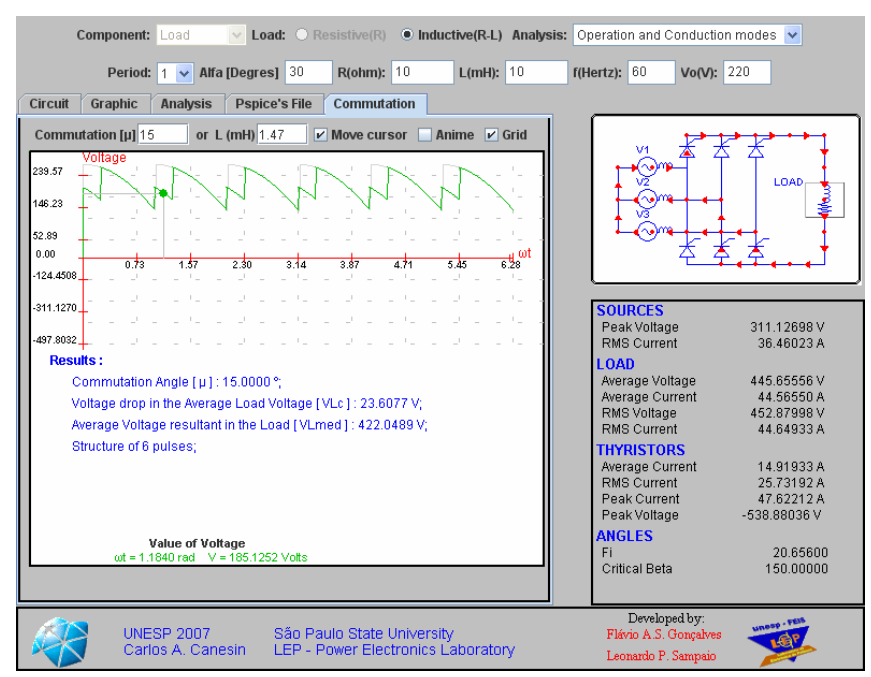

Fig. 9. Three-phase six-pulse full-bridge controlled rectifier, commutation analysis example (series inductances).

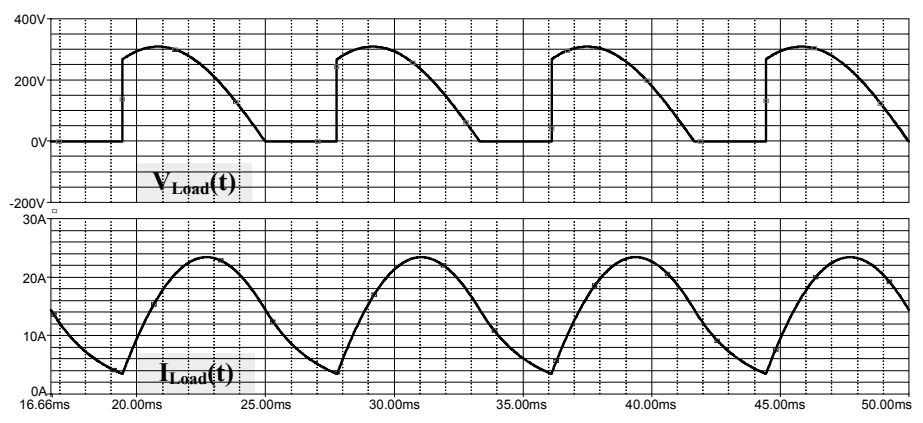

(a) Pspice Waveforms



(b) Simulation Applet

Fig. 10. Single-phase semi-controlled thyristor/diode-bridge rectifier: Pspice results versus Java Applet results.

In the actual stage is available only the content to "Power Electronic I" course. It should be noticed that all contents have been developed using open tools as PHP language and MySQL database. This way, all contents are interconnected in database, allowing shortcuts to access several topics, and in the future including some statistics related to accesses.

Figure 11 shows the summary of the Power Electronics I course (in this first version only available in "Portuguese").
TABLE I

Output voltage and Total Harmonic Distortion Analysis

\begin{tabular}{|c|c|c|c|}
\hline Magnitude & Applets & Pspice 9.1 & Error $(\%)$ \\
\hline DC Component & 150,000 & 146,593 & 2,32 \\
\hline Component Order 2 & 171,500 & 171,400 & 0,06 \\
\hline Component Order 4 & 34,275 & 34,260 & 0,04 \\
\hline Component Order 6 & 29,728 & 30,570 & 2,75 \\
\hline Component Order 8 & 24,417 & 24,470 & 0,22 \\
\hline Phase (Degrees) & Applets & Pspice 9.1 & Error (\%) \\
\hline Component Order 2 & $-121,71$ & $-119,90$ & 1,51 \\
\hline Component Order 4 & 119,52 & 120,10 & 0,49 \\
\hline Component Order 6 & $-16,93$ & $-15,91$ & 6,38 \\
\hline Component Order 8 & $-123,91$ & $-119,70$ & 3,52 \\
\hline T.H.D & Applets & Pspice 9.1 & Error (\%) \\
\hline T.H.D. [\%] & 33,80 & 34,20 & 1,17 \\
\hline \multicolumn{4}{|c|}{$\begin{array}{l}\text { TABLE II } \\
\text { Main Voltage and Current Values Analysis }\end{array}$} \\
\hline Component & Applets & Pspice 9.1 & Error (\%) \\
\hline \multicolumn{4}{|l|}{ Source $V_{1}$} \\
\hline RMS Voltage & 15,538 & 15,410 & 0,83 \\
\hline \multicolumn{4}{|l|}{ Load } \\
\hline Average Voltage & 150,000 & 146,593 & 2,32 \\
\hline Average Current & 14,782 & 14,647 & 0,92 \\
\hline RMS Current & 16,269 & 16,141 & 0,79 \\
\hline \multicolumn{4}{|l|}{ Thyristors } \\
\hline Peak Current & 6,117 & 6,060 & 0,95 \\
\hline Average Current & 10,998 & 10,899 & 0,91 \\
\hline RMS Current & 23,610 & 23,409 & 0,86 \\
\hline Peak Voltage & $-311,125$ & $-310,204$ & 0,30 \\
\hline
\end{tabular}

Figure 12 shows, as example, the chapter 3 content. Considering that chapters are divided in several pages, the top area shows the content of one page, and above there is a navigation tool where is possible to "walk" through pages.

Furthermore, each course chapter and its topics can be instantaneously accessed by the user including the connected tools and Java Applets for simulations, as shown in Figure 12. 




Fig. 11. WWW-Course: Power Electronics I content.

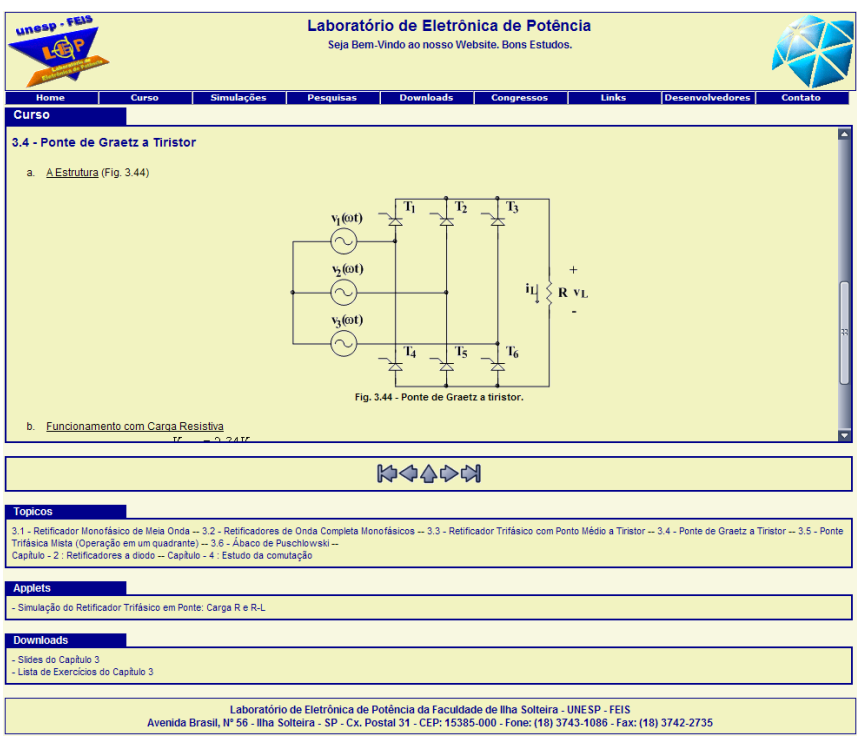

Fig. 12. Content and tools related to chapter 3.

Finally, the courseware platform for all chapters has downloadable tools where are available exercise lists, classes notes, and other related topics.

\section{LABORATORY SET-UP EXAMPLE}

The experiments are developed using a laboratory set-up including digital multimeters, digital oscilloscope, didactic rectifier modules from DEGEM Systems, and a microcomputer with internet connection, as shown in Figure 13.

In this context, through experimental analysis of a specific rectifier structure, students can compare and analyze the experimental results in relation to simulated results obtained from the proposed Java applets, as shown in Figure 14 Consequently, students can develop an accurate conclusion for experiments, through a complete analysis between the idealized simulated circuits and the real experiments, confirming and proving the concepts developed in the classes.

Finally, in the example shown in Figure 14 and Table III students can observe some non-idealities of the circuitry, such as the thyristor forward voltage drop during the interval when the thyristor operates in on state, and the thyristor commutation-angle, that reduces the average value of the load voltage.

\section{CONCLUSIONS}

This paper presented novel JAVA applets for a WWWHTML-based course in power electronics, also applied in power electronics experiments.

The information technologies bring us new perspectives for education, not only on the technologies themselves, but also on the philosophy, and strategies of instruction and learning, allowing significant changes on many aspects of undergraduate education. Java applets provide a powerful and flexible way to deliver interactive content to students. In particular, the interactive simulations allow anyone to gain new insight into the behavior of basic rectifiers learning, without previous circuitry knowledge, either without the usage of sophisticated simulation tools, as Pspice that involve cost and a long time for apprenticeship, or without the use of expensive instruments, as example an oscilloscope.

In this context, it was observed an important increase in the student's desire to learn the content of the power electronics course, when the proposed JAVA tools were included in the traditional classes, resulting in an important improvement of apprenticeship, due to the increase of student's motivation, and the increase in the student's abilities to comprehend the behavior of several rectifier circuits.

In addition, the usage of these proposed tools during the traditional laboratory experiences provide for students conditions to perform an online comparison analysis among lab-experiences and the theoretical concepts developed in the classes. The resultant approach is very efficient for education because the students are actively involved, once it allows an interactive and attractive learning system.

Finally, the novel suite of simulation tools will be available to students and teachers, free of charge, in the Power Electronics Laboratory webpage of the São Paulo State University, UNESP, and Department of Electrical Engineering-Campus of Ilha Solteira (SP)-Brazil.

\section{ACKNOWLEDGEMENT}

This work has been supported by CNPq (National Council of Technological and Scientific Development).

\section{REFERENCES}

[1] G. Hwang, "A Tutoring Strategy Supporting System For Distance Learning On Computer Networks", IEEE Transactions on Education, vol. 41, no. 4, pp. 343-343, November 1998.

[2] G. Bengu and W. Swart, "A Computer-Aided, Total Quality Approach To Manufacturing Education In Engineering", IEEE Transactions on Education, vol. 39, no. 3, pp.415-422, August 1996.

[3] H. A. Latchman, C. Salzmann, D. Gillet and H. Bouzekri, "Information Technology Enhanced Learning In Distance And Conventional Education", IEEE Transactions on Education, vol. 42, no. 4, pp.247-254, November 1999. 


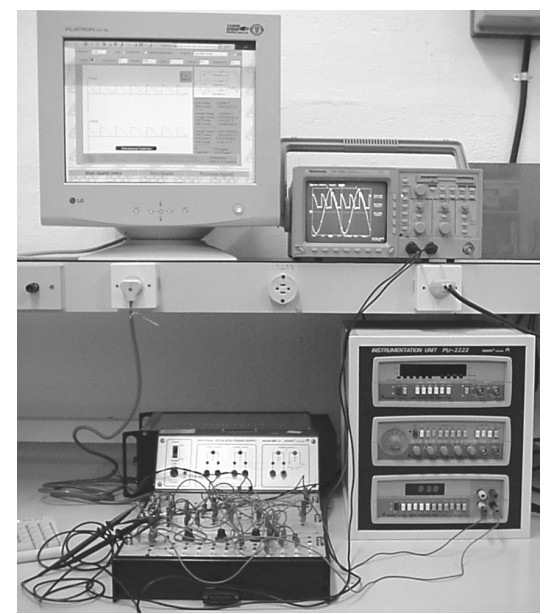

(a) Experimental Set-up

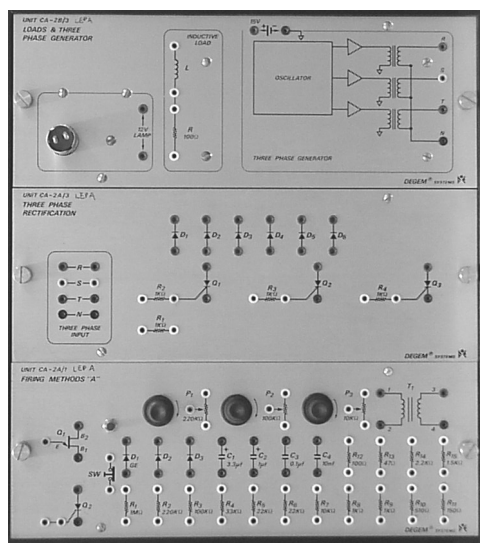

(b) DEGEM Experiment Board

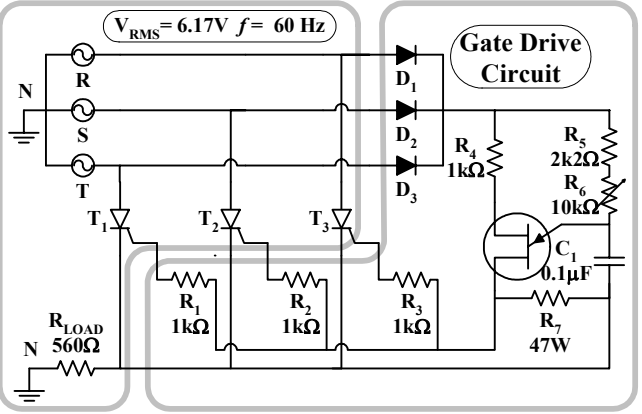

(c) Circuitry of the experiment

Fig. 13. Experimental Set-up example.

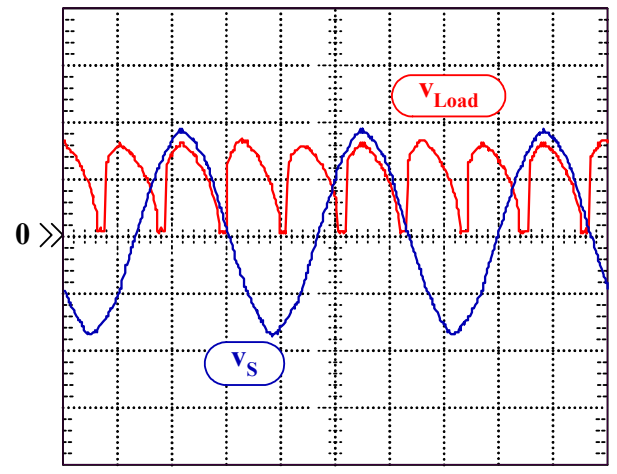

$5 \mathrm{~V} / \mathrm{div}, 5 \mathrm{~ms} / \mathrm{div}$



$5 \mathrm{~V} / \mathrm{div}, 5 \mathrm{~ms} / \mathrm{div}$

(a) Experimental results from oscilloscope.
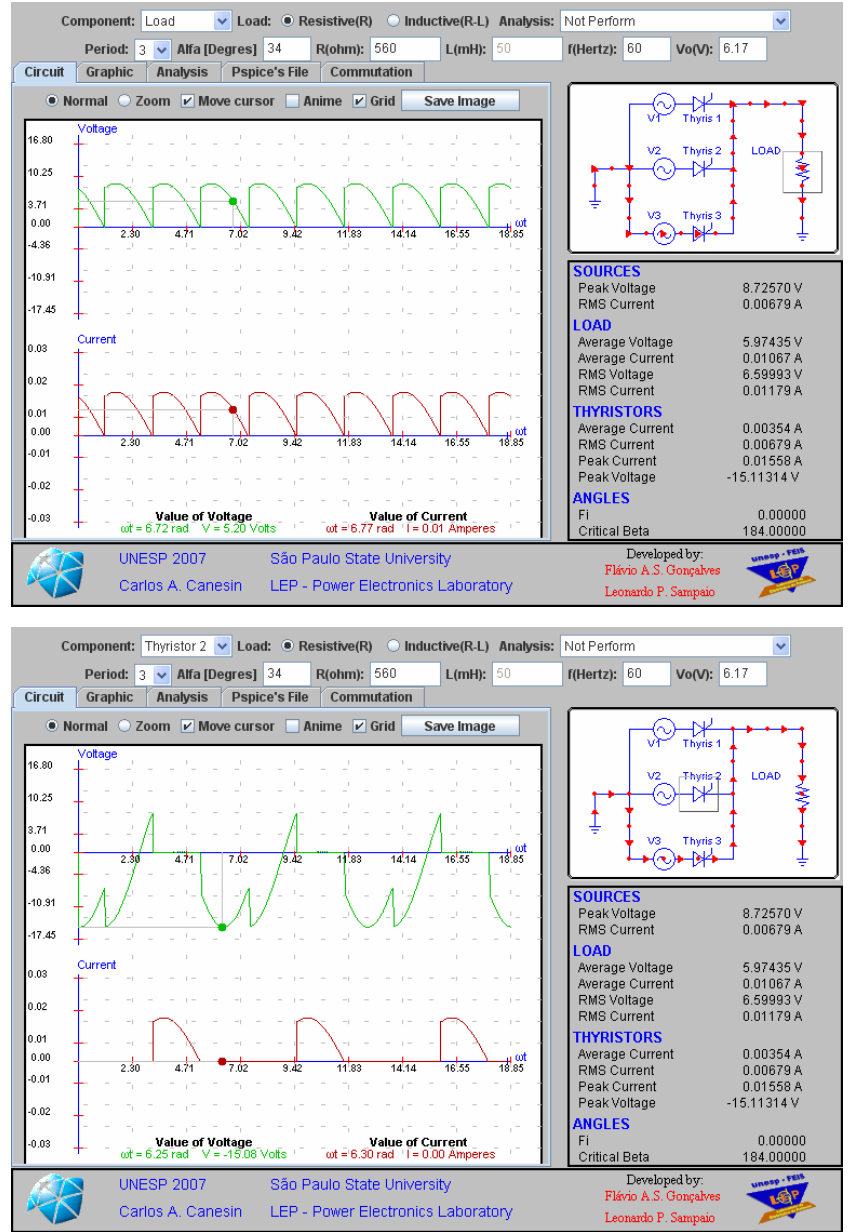

(b) Simulation results from microcomputer using the proposed tool.

Fig. 14. Comparison between experimental and simulation results.

TABLE III

\section{Load Voltage Analysis}

\begin{tabular}{cccc}
\hline Component Load & Applets & Experimental & Error (\%) \\
\hline Average Voltage & $5.97 \mathrm{~V}$ & $5.62 \mathrm{~V}$ & 6.22 \\
\hline RMS Voltage & $6.60 \mathrm{~V}$ & $6.12 \mathrm{~V}$ & 7.84 \\
\hline
\end{tabular}


[4] A. A. Renshaw, J. H. Reinbel, C. A. Zukowski, K. Penn, R. O. McClintock and M. B. Friedman, "An Assessment Of Online Engineering Design Problem Presentation Strategies", IEEE Transactions on Education, vol. 43, no. 2, pp.83-91, May 2000.

[5] M. J. Wirthlin, B. McMurtrey, "Web-based IP evaluation and distribution using applets", IEEE Transactions on Computer-Aided Design of Integrated Circuits and Systems, vol. 22, no. 8, pp. 985-994, August 2003.

[6] V. G. Agelidis, "The future of power electronics/power engineering education: challenges and opportunities", in Proc. Of IEEE Workshop in Power Electronics Education, vol. 1, pp. 1-8, June 2005.

[7] D. W. Hart, "Circuit Simulation As An Aid In Teaching The Principles Of Power Electronics", IEEE Transactions on Education, vol. 36, no. 1, pp.10-16, February 1993.

[8] I. Chamas and A. El Nokali, "Automated Pspice Simulation as an Effective Design Tool in Teaching Power Electronics", IEEE Transactions on Education, vol. 47, no. 3, pp. 415-421, 2004.

[9] V. Ramaswamy, "The online text on power electronics", available:http://services.eng.uts.edu.au/ venkat/pe_html/ peintro.htm.

[10]U. Drofenik and J. W. Kolar, "Interactive Power Electronics Seminar (iPES)-a Web-Based Introductory Power Electronics Course Employing Java Applets", in Proc. Of IEEE Power Electronics Specialists Conference, vol.2, pp.443-448, June 2002.

[11] M. Harfman Todorovic, L. Palma, P. Enjeti, "Development of new web-based materials to teach power electronics courses", in Proc. Of IEEE Workshop in Power Electronics Education, vol. 1, pp. 9-14, June 2005.

[12]P. Bauer, B. Davat, V. Fedak, V. Hajek, "Educational visualization for teaching power electronics", in Proc. Of IEEE Workshop in Power Electronics Education, vol. 1, pp.45-51, June 2005.

[13] S. Harb, K. Kalaldeh, A. Harb, I. Batarseh, "Interactive Java applets for power electronics E-learning", in Proc. Of IEEE Workshop in Power Electronics Education, vol. 1, pp. 26-33, June 2005.

[14] C. Fernández, 0. Garcia, J. A. Cobos, J. Uceda, "Selflearning Laboratory Set-up For Teaching Power Electronics Combining Simulations And Measurements", in Proc. Of IEEE Power Electronics Specialists Conference, vol. 2, pp.449-454, June 2002.

[15]R.S. Balog, Z. Sorchini, J.W. Kimball, P.L. Chapman, P.T. Krein, "Modern laboratory-based education for power electronics and electric machines", IEEE Transactions on Power Systems, vol. 20, no. 2, pp. 538547, May 2005.

[16]F. A. S. Gonçalves and C. A. Canesin, "Java Applets for a WWW-HTML-based Course in Power electronics", in
Proc. Of IEEE Power Electronics Specialists Conference, vol. 1, pp. 85-91, June 2001.

[17] F. A. S. Gonçalves and C. A. Canesin, "Educational Java applets get in power electronics labs", in Proc. Of IEEE Workshop in Power Electronics Education, vol. 1, pp. 34-39, June 2005.

[18]F. A. S. Gonçalves, C. A. Canesin and L. P. Sampaio, "Interactive Java Applets For Power Electronics Education", in Proc. Of $9^{\text {th }}$ Brazilian Power Electronics Conference, vol. 1, pp. 989-994, September 2007.

\section{BIOGRAPHIES}

Carlos Alberto Canesin, received the B.S. degree from São Paulo State University, Ilha Solteira(SP), Brazil in 1984 and the M.S. and Ph. D. degrees from the Federal University of Santa Catarina - Power Electronics Institute, Florianópolis (SC), Brazil, in 1990 and 1996, respectively, all in electrical engineering. He started the Power Electronics Laboratory LEP at the São Paulo State University, UNESP-FEIS, Ilha Solteira(SP), where he is currently a Full Professor. He was Editor-in-Chief of the Brazilian Journal of Power Electronics, Vice-president and President of the Brazilian Power Electronics Society-SOBRAEP. Currently, he is an Associate Editor for the IEEE Transactions on Power Electronics, Member of the Editorial Council of the Brazilian Journal of Power Electronics, and Permanent member of the Deliberative Council of SOBRAEP. His interests include soft-switching techniques, dc to dc converters, switchingmode power supplies, solar/photovoltaic energy applications, electronic fluorescent ballasts, active power-factor correction techniques, and modern educational tools for power electronics.

Flávio Alessandro Serrão Gonçalves, received the B.S. degree from São Paulo State University, Ilha Solteira(SP), Brazil, in 1998, and the M.S. and Ph.D. degrees from the São Paulo State University, Ilha Solteira(SP), Brazil, in 2001 and 2005, respectively, all in electrical engineering. He is currently an Assistant Professor at São Paulo State University, Ilha Solteira(SP)-Brazil. His interests include soft-switching techniques, dc to dc converters, switchingmode power supplies, digital control techniques using FPGAs and DSPs, active power-factor correction techniques, and educational tools for power electronics.

Leonardo Poltronieri Sampaio, was born in São José do Rio Preto, SP, Brazil, in 1983. He is an undergraduate student at São Paulo State University, Ilha Solteira(SP), Brazil, in electrical engineering, since August of 2004. Since 2000 , he has been working with computer programming and Linux operational systems, and actually he is a member of the Power Electronics Laboratory, LEP. His interests include computer programming, education in power electronics, elearning, education tools, java and Linux. 